\title{
APPARATUS FOR SEMIMICRO ORGANIC CHEMISTRY
}

D R. J. T. STOCK AND MR. M. A. FILL, of Norwood Technical College, Knight's Hill, London, S.E.27, are well known for their development of ingenious microchemical apparatus for use in analytical and physical chemistry. Some of this apparatus was exhibited at the International Congress on Analytical Chemistry held in Oxford in 1952. Dr. Stock and Mr. Fill, however, have not neglected the field of organic chemistry, and in the course of several years have developed a compact assembly of specially designed apparatus that covers all the general operations of preparative work and identification on a semimicro scale (cf. $J$. Chem. Educ., 30, 296 ; 1953).

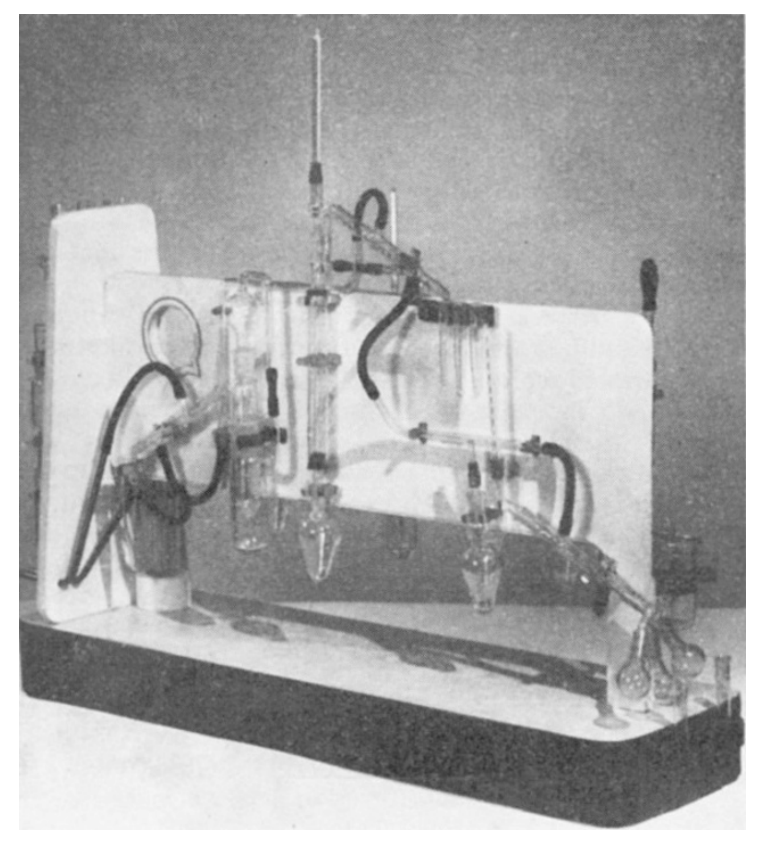

The value and utility of this assembly has now been increased by fitting the glass components with standard interchangeable ground-glass joints, and this 'vest-pocket laboratory' is being marketed by Quickfit and Quartz, Ltd. The assembly is mounted on a wooden stand, surfaced with 'Formica' laminated plastic sheet, and has a gross weight of only $14 \mathrm{lb}$. (30 in. long, 8 in. deep and 18 in. high). The base incorporates two drawers, inside which are test-tube racks and room for spare apparatus and thermometers. The handles are shaped to form additional test-tube racks. The sixty-one glass components are based on a shortened B10 joint and are held in place by Terry clips, which permit easy removal. All that is required for operation is a single connexion to a water supply, one or more simple micro gas-burners, and connexion to a vacuum for certain operations.

On the side of the centre board not visible in the illustration, the assembly incorporates a water-bath with 'ears' to support test-tubes and beakers for evaporation, a pipette for dispensing reagents and for assisting evaporation of solvents, a reflux apparatus with pear-shaped flask and all-glass Liebig condenser (these items form the vasis of the apparatus), a three-necked flask with dropping funnel and a reflux condenser for carrying out reactions, a melting-point apparatus, a continuous percolator for the extraction of solids, and a unit for distillation at ordinary pressure with a fraction collector. On the other side of the centre board are a steam-distillation unit with an anti-suck-back device, a fractional distillation unit with a simple air-jacketed column and fraotion collector, and a vacuum distillation unit with a 'pig' fraction collector. On the left-hand end of the assembly are two Willstätter and one Schwinger filters, a drying tube to fit the filters, an ice bath with 'ears' to support test-tubes, and a separating funnel.

The unit and its components bear the stamp of having been designed and made by chemists familiar with the operations to be carried out in the apparatus. The design has not suffered in the change from corks to ground-glass joints. Very often so-called micro and semimicro apparatus with ground-glass joints is practically useless through unpractical design and an unsuitable size of joint.

This assembly clearly has many possible uses. It appears particularly suitable for introducing a student, in the course of his undergraduate training, to the techniques of semimicro-scale preparative organic chemistry. In this connexion Dr. Stock and Mr. Fill have devised and used a course of experiments covering all the ordinary operations of preparative organic chemistry. This assembly, too, should be useful in research work; here the components could be used separately or easily varied by the research chemist himself for particular purposes. The assembly has many uses other than for teaching; for example, in static or mobile laboratories needing to perform organic analytical operations and, in the event of war, for the investigation (at regional level) of chemical warfare agents.

S. H. HARPER

\section{COLOMBO PLAN FOR SOUTH AND SOUTH-EAST ASIA INTERIM REPORT}

$\mathrm{O}^{\mathrm{N}}$ NE-THIRD of the six-year period 1951-57 laid down for the original Colombo Plan programmes has now elapsed, and the recently published second annusl report of the Consultative Committee on Economic Development in South and South-East Asia (New Delhi, October 1953. Cmd. 9016. London : H.M.S.O.; December 1953; $3 s .6 d$. net) attempts to take stock of the situation and the progress achieved. It was realized that the full achievement of the original objectives, which are still regarded as conceived on the right lines, would do little more than hold the existing position, because of the high rate of increase in population and the inadequacy of savings and capital investment. The population of the area, already between six and seven hundred millions, is growing at the rate of about eight millions a year; thus even to maintain present standards a continued increase in output is required, and the urgent need is to produce more food, both by opening up new 
land and by increasing the yields from land already under cultivation.

The programmes of the Colombo Plan countries can now be considered as having generally passed out of the stage of preparation into that of execution ; but broadly they are only just reaching the stage when tangible returns on any considerable scale can reasonably be expected. Most countries have devoted a large proportion of their programmes to measures which will directly or indirectly increase agricultural output. Improved means of communication and increased sources of power are also basic forms of investment and are essential whatever changes may be made from time to time in the general structure of the economy. The report also stresses the importance of developing human resources; but although not all the programmes include expenditure on such social welfare projects as health, education and housing, which would generally be regarded as adequate, the report recognizes that each country must decide for itself to what extent the growth of social capital should be promoted immediately at the cost of withdrawing capital from more-productive fields.

The successful execution of the individual development plans depends on the extent to which the main components required-capital goods, trained men and finance-are or can be made available, and each country needs continuously to review its development programme in the light of such available or anticipated resources. Although prices are still high in relation to 1950 levels, the supply of capital goods, provided that finance is available, is not expected to present undue difficulties. As regards trained manpower, the report notes a closer relationship between capital development and technical co-operation, as well as a tendency towards a better balance between training at home and training abroad. 'The shortterm emphasis on the preparation and execution of plans which will result in increased production in the shortest possible time has encouraged in some countries much reliance on experience and techniques which are at present only available from abroad, whereas longer-term interests demand the development of training facilities in the countries of the region to provide the millions of medium- and lowergrade technicians who will be required in every branch of industry and administration and who can only be trained in their own countries.

Technical co-operation funds have in consequence been used for establishing and equipping training institutions; although it takes time to develop institutions of this character, unless a start is made now some of the projects already launched may wither away for lack of a supply of trained technicians to operate and expand them. The Technical Co-operation Scheme may have a special part to play also in the provision of equipment for such training institutions. Moreover, the basic concept of the Colombo Plan has been co-operation, with each country doing what it can to assist in the development of the area as a whole. Development schemes in operation in any particular country of the region are likely to be repeated elsewhere with certain modifications, and planners, managers, engineers and trainees can often learn more from such a project in the area than from a completed project in a developed country where conditions may differ widely from those in the region. To promote this kind of training, the Council for Technical Co-operation has agreed that capital expenditure on buildings is a proper charge on a country's contribution to the scheme, provided that substantial benefits are offered to other countries in the area.

The third factor-finance-presents the greatest difficulty ; the countries of the region no longer enjoy the very favourable terms of trade which prevailed for most of them in 1950-51. The prices of most of the exports in 1952-53 had fallen considerably, the terms of trade appreciably worsened and public revenues decreased, while budget deficits replaced, or threatened to replace, the overall budget surpluses of the boom period. Under these conditions, the Governments concerned maintained or increased their expenditure on development only by drawing heavily on their reserves, by external aid in the form of loans or grants, or by raising internal loans. Some even engaged in deficit financing, by borrowing from the banking system to meet their current expenditure.

The risk of inflation is inherent in any intensive investment effort; but the report points out that deficit financing seriously aggravates this riskbecause the consequences of inflation are particularly serious in most countries of the area, deficit financing can only be used to a limited extent. The Colombo Plan programmes are, it is concluded, reaching a critical stage, and their success depends on, besides concentration on the essentials and the fullest use of all available resources, sound internal policies designed to check inflation and secure the highest possible level of saving and investment, and the continuance of external financial aid at least at its present level. Although there has been an appreciable increase in domestic private investment in most of the countries, foreign capital is also required, and the report suggests that a hopeful approach is to invite such capital on a specific project basis on mutually agreeable terms. Finally and significantly, the report notes that the dependence of the area on world markets means that the success of plans for future development largely turns on the outcome of international discussions and the reviews of national economic and trade policies currently proceeding.

\section{NEW NATURE RESERVES IN GREAT BRITAIN}

$\mathrm{T}$

HE following six areas in England were declared as new nature reserves on March 9 by the Nature Conservancy : the 514 acres of the Woodwalton Fen, Huntingdon; the addition of 10 acres, known as West Wood, to the Monk's Wood Nature Reserve, already declared on July 1, 1953 ; the 1,628 acres of sand-dunes, salt marsh and shingle ridges at Scolt Head, Norfolk, acquired by the National Trust in 1923 , to which a further 197 acres will shortly be added; the 246 acres of shingle spit at Orfordness and the adjacent 264 acres at Havergate Island of the Orfordness-Havergate Nature Reserve on the Suffolk coast, under agreement with the Royal Society for the Protection of Birds ; 140 acres at Old Winchester Hill, 400-670 ft. above sea-level, in Hampshire; and the five acres of the Swanscombe Skull Site Geological Reserve in the disused Barnfield Gravel Pit in North Kent, which includes much unworked gravel available for research.

Woodwalton Fen has very rich fen flora, including an abundance of species which occur but sparingly 